\title{
SHORTER CONTRIBUTIONS
}

551.508 .5

\section{The Change of Rotational Speed of Cup Anemometer for Marine Use due to Rolling and Suspected Cause of Its Damage}

\author{
by \\ M. Sanuki and S. Kimura ' \\ Meteorological Research Institute
}

(Received June 19, 1953)

Four cup-anemometers were installed on board the M.S. Nissei Maru for the purpose of wind speed measurement during the progressive and other tests conducted by the Ministry of Transportation, University of Tokyo and ship-builders of Japan in the winter 1951 52 at the North Pacific. All cup anemometers, however, were completely destroyed at the earliest stage of navigation even though the wind speed encountered slightly exceeded $20 \mathrm{~m} / \mathrm{s}^{*}$ while the reserve windmill anemometer Speedovane [1] survived and functioned satisfactorily until the last stage of the tests.

Recently we have carried out the wind tunnel test of a standard cup anemometer, tilting the plane of rotation, as a preliminary research on marine anemometers. The four anemometer cups are of $8 \mathrm{~cm}$ in diameter and have cup-center arm length (radius) of $14 \mathrm{~cm}$. The results are illustrated in Fig. 1 as the ratio of rotational speed for the tilt angle $\theta$ (ship rolling angle) upward or downward from the horizontal, to that for untilted position.

It can be seen :

1) The rotational speed ratio is constant only for tilt angle of $\theta=15^{\circ}$ or less,

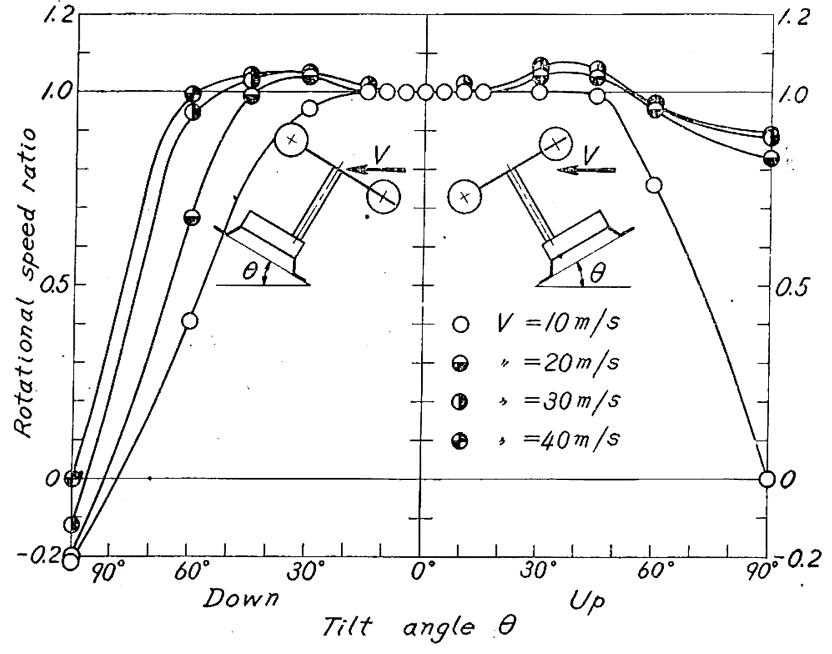

Fig. 1. The influence of tilt angle upon the rotational speed of cup anemometer (M.R.I. wind tunnel).

* Private correspondence from Prof. INUr, University of Tokyo. 
both upward and downward.

2) Then it slightly increases with $\theta$ except for lower wind speed $V$, and rapidly decreases especially with downward $\theta$, where even counter-rotation is apparent.

3) The asymmetry of the curve for unward and downward tilt angle is remarkable, e.g., $30 \%$ rotational speed difference between $\theta=60^{\circ}$ upward and downward at $V=20 \mathrm{~m} / \mathrm{s}$.

The ordinary cup-anemometer arm is not provided with the allowance of fatigue strength for such large rotational speed variation, which must further tolerate the presence of the bending moment due to out-of-plane air force and the gyroscopic moment due to ship's rolling. Although the necessary strength calculation is not yet carried out, some reinforcement should be recommended with respect to the cup arm, in case an ordinary cup anemometer for land use is installed on board ships.

\title{
Reference
}

[1] Sanuki, M., Krmura, S. and Tsuda, N. 1951: Studies on Biplane Wind Vanes, Ventilator Tubes and Cup Anemometers. Papers in Meteorology and Geophysics, 2, p. 317.

551.508 .5

\section{Note on the Design of Anti-Freezing Windmill Anemometer with the Torque Load of Slip Ring}

\author{
by \\ M. Sanuki and S. Kimura \\ Meteorological Research Institute \\ (Received June 19, 1953)
}

Recently we have reported the test results on an anti-freezing combination wind vane and anemometer (Anti-Freeze Speedovane) on the summit of Mt. Fuji [1]. The blade electric heater inevitably imposes a torque load due to slip ring upon the windmill shaft, and its influence on the rotational speed is tested in the $1.5 \mathrm{~m}$ wind tunnel of the Institute as illustrated in Fig. 1. The torque load is varied by adjusting the spring-loaded screws of the siip ring, and its amount is measured by static weights placed upon one of the windmill blades. In the figure the rotational speed 